REVISTA ANDALUZA DE ANTROPOLOGÍA.

NÚMERO 6: LOS MOVIMIENTOS SOCIALES Y LA CONSTESTACIÓN AL ORDEN GLOBAL.

MARZO DE 2014

ISSN 2174-6796

[pp. 120-142]

http://dx.doi.org/10.12795/RAA.2014.i06.06

Fecha de Recepción: 10-03-2014

Fecha de Aceptación: 19-03-2014

\title{
LOS INDIGNADOS DEL 15-M EN EL CONTEXTO DEL MOVIMIENTO ALTERGLOBALISTA. ENTRE EL OBRERISMO Y EL REPUBLICANISMO
}

\author{
Agustín Coca \\ Ángel del Río \\ Universidad Pablo de Olavide \\ Félix Talego \\ Universitad de Sevilla
}

\section{Resumen.}

Pretendemos analizar el ciclo de movilizaciones habidas en España y conocidas como movilizaciones del 15-M o de los indignados, en el marco de la tensión que subyace en ellas, según pretendemos mostrar, entre el sustrato obrerista y el sustrato republicanista. Las ideologías obreristas dominaron incontestadamente las expresiones de protesta y reclamos en el espacio público hasta los años sesenta del siglo pasado, condicionando incluso las protestas de temática no obrera. El ecopacifismo-feminismo viene abriéndose paso desde entonces y condiciona los significados y las expresiones públicas de protesta conforme a otros vectores. Obrerismo y ecopacifismo-feminismo son paradigmas de pensamiento diferentes en esencia, aunque la realidad de las organizaciones y los movimientos los muestren amalgamados con frecuencia. Ilustramos esto en el plano de las acciones simbólicas en el espacio público. Y hemos creído pertinente limitar la atención al período comprendido entre las huelgas generales del 29 de septiembre de 2010 y del 29 de marzo de 2012, convocadas ambas por los sindicatos contra sendas reformas laborales. 


\title{
Palabras clave.
}

Obrerismo, republicanismo, ritual político, nuevos movimientos sociales, movimiento de los indignados.

\begin{abstract}
.
In this article we aim to analyse the mobilisations which took place in Spain thar were known as the M-15 mobilisations or the indignados (indignants), in the frame of the tension between both the workerist and the republicanista (citizenist) backgrounds. Workerist ideologies were undoubtedly dominant in the protest expressions and reclaims about the public space until the 1960s, conditioning even the protests which were not stricktly related to the working class. Ecopacifism-feminism has been breaking through since then and is influencing the protest meanings and public manifestations with other vectors. Workerism and ecopacifism-feminism are essentially different thinking paradigms, although they use to appear mixed in organisations and movements. We illustrate this in the ambit of symbolic actions in the public space. We have limited our study to the period between the general strikes of September 29, 2010 and March 29, 2012, both convoked by trade unions against Labour Law Reforms.
\end{abstract}

\section{Keywords.}

Workerism, citizenism, political ritual, new social movements, indignados movement.

\section{Descripción sumaria del ciclo de movilizaciones elegido}

El ciclo de protestas que vamos a analizar se inicia en respuesta a los recortes decretados por el gobierno del PSOE en mayo de 2010, entre los que destacan la rebaja del 5\% del sueldo de los funcionarios y empleados públicos y la congelación de las pensiones, aprobadas el 13 de mayo de $2010^{1}$. A dichos recortes debe sumarse la Reforma Laboral del 9 de septiembre del mismo año ${ }^{2}$. Como reacción a estas medidas, los sindicatos llamados mayoritarios convocan la huelga general del 29 de septiembre de $2010^{3}$. El seguimiento

1. Real Decreto-ley 8/2010, de 20 de mayo, por el que se adoptan medidas extraordinarias para la reducción del déficit público: http://www.boe.es/boe/dias/2010/05/24/pdfs/BOE-A-2010-8228.pdf.

2. Ley $35 / 2010$, de 17 de septiembre, de medidas urgentes para la reforma del mercado de trabajo («BOE» núm. 227, de 18 de septiembre de 2010, páginas 79278 a 79326).

3. Los sindicatos CC.OO y UGT difundieron un manifiesto justificando la Huelga General: http://www. ugt.es/huelga general/index29manifiestohuelgageneral.html. La prensa se hizo eco de las razones de la Huelga: http://elpais.com/elpais/2010/06/11/actualidad/1276244243 850215.html; http://www.elmundo.es/ mundodinero/2010/06/14/economia/1276514984.html. 
fue desigual y en los días sucesivos los sindicatos reclamaron la necesidad de negociar sin éxito y sin lograr desviar los planes del gobierno ${ }^{4}$.

El incremento de la especulación con la deuda del Tesoro entonces y en los meses sucesivos, más las noticias sobre los recortes drásticos en otros países periféricos de la UE y las recomendaciones de Bruselas, el Banco Central Europeo y el FMI (la "troika") en el sentido de proseguir los recortes, el cuestionamiento del sistema de pensiones, etc, contribuyeron a elevar un estado de inquietud e incluso indignación en amplios sectores de la ciudadanía, sin que encontrara oportunidad o cauces adecuados de expresión desde la huelga general aludida y por más de seis meses.

Esta "tensión acumulada" contribuye a explicar el éxito sorpresivo de la convocatoria de manifestaciones el 15 de mayo, realizada por la plataforma DRY (¡Democracia Real Ya!), nacida en Internet solo unos meses antes. La movilización del 15-M y las acampadas en las plazas de las ciudades, que se prolongaron hasta mediados de junio, presenta muchos elementos novedosos y es realmente un acontecimiento singular en España desde la transición política a la monarquía parlamentaria. En lo fundamental porque como analizaremos en la segunda parte con más detenimiento- irrumpen en la campaña electoral y logran desplazar sustancialmente el protagonismo de los partidos y candidatos que concurrían a las elecciones locales celebradas el 22 de mayo de 2011, hecho que no había ocurrido nunca en el régimen democrático vigente.

Los temas de denuncia predominantes entre los manifestantes y en las acampadas giraban en torno a la condición ciudadana secuestrada. Los slogans "No nos representan" $y_{\text {¡ }}$ Democracia Real Ya! lo sintetizan perfectamente. Sin embargo, las demandas clásicas obreras y en general laborales escaseaban y quedaron netamente ensombrecidas por las primeras. La ausencia prácticamente total entre los manifestantes de representantes sindicales y de partidos políticos y sus correlativos discursos sobre la necesidad de "crecer y crear puestos de trabajo", remarcaba aun más este opacamiento o postergación de lo laboral y obrero por lo ciudadano.

$\mathrm{Al}$ respecto, queremos hacer notar el contraste indudable entre estas movilizaciones de mayo de 2011 y las inmediatamente anteriores movilizaciones importantes y generales en el territorio del Estado, las arriba mencionadas de la huelga del 29 de septiembre (solo ocho meses antes). Entre una y otra movilización se constatan cambios tan notorios que podría hablarse de una oscilación pendular:

A) Huelga de 29 de septiembre de 2010: es un acto en la que el simbolismo dominante

4. http://www.publico.es/espana/339139/; http://elpais.com/diario/2010/09/30/espana/ 1285797601_ 850215.html\#despiece1. 
es convencionalmente obrerista ${ }^{5}$, con protagonismo de los sindicatos ${ }^{6}$, sus jerarcas, su jerga centenaria con eje de lo obrero y el trabajo, sus banderolas y colores y su discurso protocolario final que, en esta ocasión, como desde hace mucho tiempo, no atrajo la atención y, por supuesto, no despertó el entusiasmo de los congregados. Estos, mayormente, se desentienden del discurso final de los líderes, con sus rutinarias retahílas de agravios entreveradas de preces al gobierno y retóricas amenazas a la patronal. No obstante, los referidos líderes detentaron incuestionadamente el uso exclusivo de la palabra política en el acto.

B) Movilizaciones del 15-M en mayo de 2011: la primera ola de movilizaciones se prolongó hasta mediados de junio a través de las acampadas en las plazas de todas las ciudades y muchos pueblos de la geografía española. La segunda ola de este ciclo del 15-M se produce el 19 de junio, logrando otra vez que multitudes variopintas, en número desacostumbrado en España desde la movilización contra la guerra de Irak en 2003, saliesen a la calle y se congregaran masivamente en las plazas, convocadas por los mismos actores que la anterior de mayo. La tercera convocatoria importante y unitaria de los ya entonces conocidos dentro y fuera de España como "indignados" es el 28 de agosto. En esta ocasión el motivo para la convocatoria realizada por entidades como ¡Democracia Real Ya! y Juventud Sin Futuro era más concreta: el repudio a la reforma de la Constitución acordada por el PSOE y el PP para que incluyese un tope de déficit y la prioridad al pago de la deuda soberana. Los convocantes exigían un referéndum para que la ciudadanía se pronunciase al respecto. Aunque se trató también de una movilización amplia, concurrida y general por todo el territorio estatal, ya en esta ocasión pudo comprobarse una capacidad de convocatoria muy inferior a las dos anteriores.

Se trata en todos los casos de actos de un simbolismo resueltamente ciudadano, por tanto, de sujetos que reclaman su derecho a decidir en igualdad en el marco de la comunidad política. Repasando las imágenes de las marchas y las acampadas, las consignas más repetidas (“¡Democracia real ya!”; "No nos representan”...), las pancartas caseras, los

5. Concepción del sujeto que lo considera centralmente como productor o, lo que en términos de las ideologías modernas viene a ser confluyente y partícipe del supuesto proceso general de "creación" de riqueza.

6. A lo largo del texto cuando nos referimos a los sindicatos lo hacemos con relación a las grandes centrales sindicales (CCOO y UGT) que, en definitiva, son las que convocan unilateralmente las huelgas generales en fechas señaladas bajo lemas concretos y los que tienen una mayor capacidad de movilización, representación y negociación. Es cierto que existen otros sindicatos, llamados alternativos, entre los que incluimos para Andalucía a la CGT, el SAT, la USTEA y la CNT entre otros más minoritarios, que no responden al modelo de los anteriores y, aunque en muchos de ellos predomine el discurso "obrerista", determinadas acciones se podrían alinear en lo que hemos llamado movimiento ciudadanista en la línea marcada por los nuevos movimientos sociales (Roca, B.; Díaz, I., 2012). 
temas que se debatían en las asambleas, se constata una diversidad de quejas y proclamas, pero con un contenido general de signo ciudadano y no específicamente obrero. No afirmamos que no estuviesen presentes, amalgamadas con otras, reclamaciones obreras, pero estaban diluidas en el conjunto y no tenían en absoluto el protagonismo. En todo caso, lo obrero se encontraba subsumido entre otros muchos factores. Muy diferentes pues en su significación y alcance estas movilizaciones a las clásicamente obreristas del 29 de septiembre de 2010 con las que hemos comenzado el análisis.

Después de las manifestaciones de los indignados del 29 de agosto, las distintas asambleas que se reclaman herederas han ido convocando acciones diversas y fragmentarias, más o menos minoritarias, más o menos exitosas, como constituir asambleas 15-M por los barrios, constituir diversas plataformas, entre las que han tenido más repercusión las que hacían frente a los desahucios de viviendas familiares. A partir de entonces se ven florecer todo tipo de iniciativas progresivamente más descoordinadas y heteróclitas, produciendo inevitablemente una cierta diseminación y pérdida de potencial de impacto mediático, si bien las acciones contra los desahucios (como los llamados escraches) vienen teniendo, como decimos, mucha repercusión y han obligado a pronunciamientos diversos de los jefes de los partidos y otras entidades. Sea como sea, es un hecho que la movilización del 29 de agosto de 2011 es -hasta el momento de escribir estas líneas al menos- la última de las masivas y generalizadas acciones del ciclo del 15-M o de los indignados.

Es entonces que el movimiento pendular aludido comienza un cambio de signo, porque el 6 de septiembre los sindicatos "mayoritarios" CCOO y UGT convocan en las principales ciudades marchas con el lema No a esta reforma de la Constitución, referéndum ya. Exigían una consulta popular sobre la reforma de la Constitución acordada por PP, PSOE y la adhesión de Unión del Pueblo Navarro (que, recordemos, consistió en incluir el principio de estabilidad presupuestaria en su articulado). La convocatoria estuvo apoyada por IU y, según la prensa, por más de doscientas entidades. Los convocantes de las movilizaciones del 15-M (DRY, Juventud sin Futuro) no se sumaron a la convocatoria sindical, sino que organizaron su propia marcha, si bien en Madrid, Sevilla y otras ciudades confluyeron al final con la marcha encabezada por los sindicatos ${ }^{7}$. Aunque es preciso señalar que en algunas ciudades las asambleas del 15-M se sumaron a la convocatoria de los llamados sindicatos alternativos (CGT, SAT, CNT, USTEA) que convocaban una manifestación con recorrido y horario distinto a la de los sindicatos mayoritarios. En otros casos, las asambleas optaron por adherirse a ambas convocatorias.

Se trata, lo reiteramos, de una oscilación pendular cargada de significaciones, algunas de las cuales conviene señalar aquí para analizarlas en la segunda parte del artículo: reaparecen los sindicatos, que habían estado prácticamente ausentes del espacio público y la actualidad mediática desde hacía un año (huelga general del 29 de septiembre de

7 http://elpais.com/diario/2011/09/07/espana/1315346410 850215.html. 
2010). Ellos traen de nuevo a la calle el obrerismo, que va de suyo con su presencia, pues les es consustancial, al tratarse de entidades que se definen por la defensa de los intereses de sujetos en tanto que asalariados. Por tanto, la presentación pública de la ciudadanía que se manifiesta tras sus pancartas y banderolas es hecha, quiéranlo o no, sean conscientes o no, destacando, anteponiendo, su condición de trabajadoras y trabajadores asalariados, o en nombre de ellos. Así fue también en esta ocasión, aunque la demanda no fuese específica ni directamente obrera (demanda de referéndum sobre la reforma de la Constitución, según queda dicho), sino genéricamente ciudadana. Se trató pues de una demanda típicamente ciudadana, solo que convocada ahora por entidades "obreristas". Prolongando esta interpretación, podría afirmarse que el obrerismo se erigió en esa ocasión en vanguardia de la totalidad ciudadana; obrerismo y sus sindicatos "mayoritarios" como garantes de los derechos ciudadanos. Por supuesto que no era la primera vez que ocurría esta suerte de transacción, o sinécdoque, o metonimia (según se mire), pero nos parece revelador subrayarlo para esta ocasión, puesto que consideramos estratégico destacar la tensión obrerismo-republicanismo para entender el ciclo de las movilizaciones del 15-M y su devenir.

Tras los sindicatos, en esta ocasión del 6 de septiembre que comentamos, aparecieron algunos partidos de izquierda, como IU. La presencia de los partidos en la calle, de todos, había quedado arrinconada por los indignados desde el 15-M hasta esta fecha, dado que su presencia en los mítines en las elecciones locales de mayo había pasado prácticamente desapercibida para propios y extraños, atentos todos a las manifestaciones y acampadas de los indignados. Pero a esta convocatoria de los sindicatos del 6 de septiembre se adhirió IU, como otras entidades de diverso tipo. Por eso sostenemos que la movilización del 6 de septiembre representa el comienzo de la oscilación pendular: porque los actores convencionales o tradicionales que han venido ocupando el espacio público con más frecuencia para vindicar desde la transición volvían a donde habían sido desplazados, aunque fuera en esta ocasión con un tema eminentemente ciudadano y no singularmente obrero; el sindicalismo obrerista recuperaba la calle, si bien que aprovechando inquietudes y malestares genéricamente ciudadanos ${ }^{8}$.

¿Y los indignados?: si hubiera que considerar a las personas indignadas, en tanto que sujetos, individualmente considerados, habría que referir que un número considerable de ellos, de los que habían prestado su presencia a las movilizaciones solo unos meses antes, iban ahora arracimados tras los sindicatos "mayoritarios". Eran los mismos, y nada nos permite suponer que hubiesen cambiado su análisis y su posicionamiento político. Pero esta perspectiva de privilegiar la atención a los individuos no es fecunda: en el

8. No procede aquí señalar la más que probable maniobra de las cúpulas sindicales para "recuperar la calle" y desplazar el asamblearismo del 15-M: lanzar ellos una convocatoria con el tema protagonista de esas asambleas, la demanda ciudadana constituyente. 
tema que nos ocupa, como en general, el individualismo metodológico no nos da la clave. Lo relevante -o al menos lo más relevante- no era lo que pensaran, creyeran e hicieran una a una y sumatoriamente todas las personas que se movilizaron, sino que, al ir tras la pancarta de los sindicatos, aceptaban en los hechos prestar su número y su voz a esas entidades ${ }^{9}$, y, de forma más o menos consciente, constituían un colectivo, un actor social que, al ser numeroso, dotaba de fuerza legítima a los portavoces sindicales y los resituaba (resucitaba) como interlocutores válidos junto -o frente- a otros actores y las instituciones públicas.

Este respaldo a los sindicatos ocurría - no hay que olvidarlo- solo unas fechas después de que muchas de las mismas personas se sumaran al coro del "no nos representan" de los indignados, grito que se lanzaba en genérico, contra todas las entidades de representación existentes en el Estado español, incluidas las sindicales. Las entidades ¡Democracia Real Ya!, Juventud sin futuro y otras de las convocantes del 15-M perdían ya el protagonismo en esta ocasión del 6 de septiembre: estas entidades indignadas y sus proclamas de denuncia de la farsa democrática, cuando habían tenido hasta hacía poco todo el espacio público para ellas, desfilaban ahora ya en la cola de las manifestaciones protagonizadas por los "sindicatos mayoritarios"

La siguiente ocasión importante de ocupación del espacio público con señalado contenido político se produjo con motivo de la campaña electoral de las elecciones generales de 20 de noviembre de 2011. Durante la campaña electoral, el protagonismo de los indignados fue netamente inferior al que lograron en la campaña electoral a las elecciones municipales, como queda referido. Ahora, el protagonismo, acostumbrada y rutinariamente, volvía a estar en los mítines, y los reportajes de los medios podían ya ocuparse en los detalles del carácter de los jefes políticos, las descalificaciones entre candidatos y los contenidos gruesos de los respectivos programas electorales.

El nuevo gobierno del Partido Popular, ganador en estas elecciones, promulgó otra reforma laboral en un tiempo record, publicada en el BOE el 10 febrero 2012 (solo dos meses y medio después de la investidura de Mariano Rajoy) y publicitada por los lugartenientes del partido gobernante como una palanca fundamental para volver a situar a España "en el buen camino de la senda del crecimiento y de la creación de empleo". El protagonismo otorgado por el gobierno Rajoy al "crecimiento y la creación de empleo" contribuía decisivamente a recolocar la perspectiva obrerista en el centro del debate público y cooperaba objetivamente con los sindicatos "mayoritarios" en tal dirección: aunque gobierno y sindicatos tuviesen perspectivas distintas, incluso enfrentadas, sobre

9. Como argumenta entre otros Roy Rappaport, en los rituales y acciones simbólicas, lo relevante, lo que se registra y cuenta, no es lo que se cree, puesto que la creencia es difícil de concretar y definir, y es privada. Lo que cuenta es la aceptación, que es un acto público, que puede o no implicar creencia, pero que, ante todo, compromete públicamente (Rappaport, 2001: 183). 
el cómo, coincidían ambos en el discurso, central de nuevo, de que todo debe orientarse al objetivo de "crear" riqueza, porque ella a su vez "creará" puestos de trabajo (o a la inversa, tanto da). El resto de actores relevantes, como los partidos, los grandes medios de formación de masas (medios de comunicación) se sumaba sin reparos al tradicional discurso e, inevitablemente, la protesta en la calle quedaba ya sólidamente polarizada en torno al eje de la "creación de puestos de trabajo" y la mejor vía para lograrlo.

La oscilación pendular se consumaba así y los sindicatos, de nuevo protagonistas en la calle, convocaban una jornada de movilizaciones el día 19 de febrero, previa a la huelga general que ya preparaban para el 29 de marzo. En las dos ocasiones, por supuesto, las tradicionales proclamas del sindical-obrerismo recuperaron la centralidad y, si en la cola de las manifestaciones permanecían otras proclamas, las que habían sido propias de los indignados, estaban ya en función o supeditadas a la cuestión obrero-sindical. Los sindicatos "mayoritarios" y su obrerismo constitutivo habían vuelto por donde solían: a ser protagonistas y llevar la voz cantante en las grandes ocasiones en las que la ciudadanía se hace presente en el espacio público para demandar y/o denunciar a los poderes públicos.

El ciclo de protestas que hemos querido resaltar para poder sustanciar nuestras hipótesis, comenzaba y terminaba con sendas huelgas generales convocadas por los sindicatos "mayoritarios", la del 29 de septiembre de 2010 y la del 29 de marzo de 2012. Pero entre una y otra habían tenido lugar las grandes movilizaciones de los indignados del 15-M. ¿Podría afirmarse entonces que el republicanismo impugnador ha sido un paréntesis en una normalidad sindical-obrerista?

\section{Análisis del ciclo}

Procederemos en la segunda parte del texto a analizar algunos de los conflictos que se han expresado simbólicamente en el espacio público de calles y plazas durante el período considerado, aquellos que nos parecen más reveladores de las propuestas políticas en liza: la tensión subyacente entre los que llamaremos obrerismo y republicanismo; la expresión de ese conflicto en los tipos de acciones simbólicas y, particularmente, la repercusión de las acampadas en el ritual electoral de las municipales de 2011. Por último, consideraremos si el 15-M es un nuevo movimiento social o más bien un nuevo ciclo de movilizaciones donde se han expresado reclamos de los movimientos sociales no obreristas surgidos en los años sesenta.

\section{Obrerismo-republicanismo}

Entendemos aquí por "obrerista" cualquier concepción del sujeto que lo considera centralmente como productor o, lo que en términos de las ideologías modernas viene 
a ser confluyente y partícipe del supuesto proceso general de "creación"10 de riqueza. La noción de trabajo - compartida sólidamente, como noción de sentido común- en el obrerismo es la que madura a partir del siglo XVIII de la mano de la filosofía económica liberal, adoptada después por $\operatorname{Marx}^{11}$ : aquellas actividades humanas que, supuestamente, "producen" y "acrecienta" la riqueza y que, por contribuir a ello, son elevadas a la condición de principales entre todas las actividades humanas posibles, ya que, de su prosperidad pende la prosperidad del conjunto social, y viceversa.

El obrerismo se caracteriza en su expresión simbólica en el espacio público por mostrar de variadas formas que la definición axial que proponen de sí los sujetos es la de trabajadores (que tienen empleo, lo buscan o se preparan para emplearse) que, en tanto que tales, pretenden legitimidad para reclamar derechos que estiman mermados o conculcados. El principio subyacente es que el trabajo así entendido es la condición para el progreso social y aún para la continuidad de la sociedad y, por ende, debe ser la llave que abra

10. Para el obrerismo, la riqueza no es un patrimonio finito que los dioses o la biosfera han generado y que debe ser administrado, sino una obra creciente y progresiva que los seres humanos edifican tomando como base la naturaleza y por medio de útiles también progresivamente eficaces. Por tanto, el obrerismo concibe al ser humano como homo faber y, en coherencia, considera que la humanidad tiene su comienzo allí donde los antropoides comenzaron a utilizar útiles (Munford, 1971).

11. Puede sostenerse pues que tal noción de trabajo es liberal y es marxista (liberal-marxista), pero será el marxismo el que la disemine y enraíce en las capas populares occidentales, reinventadas ya por esta tradición como proletariado, lumpemproletariado, vanguardia de... Pues Marx, como sabemos, sintetiza en su concepción filosófica las tres corrientes principales del pensamiento decimonónico: la filosofía clásica alemana (Hegel y Feuerbach ante todo), el socialismo francés (Proudhon) y la economía política inglesa (Ricardo) (Morris, 1995). Y en la obra de David Ricardo estaba ya planteada la idea de trabajo como el factor que "crea" la riqueza al transformar "productivamente" la naturaleza (Naredo, 1995: 95; Naredo, 2010: 180; Díez, 2001: 47-56; Gorz, 1991: 28-30). Cierto que el marxismo da al conjunto un sentido diferente, pero sin cuestionar las formulaciones teóricas de aquéllos. Mas aun, Marx, aunque muy influido por el materialismo de Feuerbach en el modo de concebir la relación humano-naturaleza, se distancia del pensador alemán al plantear que la relación del hombre con el medio es activa y transformadora, mediante el trabajo precisamente. Yace aquí, también para la izquierda obrerista de los siglos XIX y XX, como para el liberalismo, una santificación de la idea moderna de trabajo, como vía ascética de salvación intramundana, como ya lo viera Max Weber (Weber, 1969). No obstante, la exégesis más penetrante sobre la idea moderna de trabajo la realizó H. Arendt (Arendt, 1996: Cap III y IV), a la par que evidenció que fueron los propios economistas liberales, antes que Marx, quienes precipitan el "auge de lo social" y pretenden legitimar la crematística individual en base a la "ficción comunista" de la mano invisible. Marx piensa conforme a los mismos marcos, solo que su "ficción comunista" no es la armonía de la mano invisible, sino el conflicto de clases. Pero él, como los otros, tenían en perspectiva el desarrollo de las fuerzas sociales (Arendt, 1996: 54). 
la puerta a todos los derechos, siendo los primeros el derecho al propio trabajo y a los productos y beneficios que hace posibles. El obrerismo se sustancia simbólicamente en el espacio público en indumentarias, colores (rojo), consignas y proclamas, amén, por supuesto, de la identidad de las entidades convocantes ("sindicatos de clase obrera" y partidos social-comunistas).

Privilegia una concepción estructural de nuestras sociedades: la división entre propietarios y no propietarios de los medios de producción; burgueses y obreros. Bien que propende a trascenderla hacia un estadio ya universalmente integrado por laborantes. Y tiende a orientar todos los conflictos y propuestas políticas en la dirección del que sería el conflicto fundamental, el que enfrenta al "mundo del trabajo" con el "mundo del capital" o "de la patronal". En la versión liberal el esquema es idéntico, aunque con distinta terminología ("emprendedores", "operarios", etc), y considerando que la relación entre los dos actores colectivos fundamentales no es -no debe ser- de conflicto, sino de armonía. Finalmente, en el obrerismo, en cualquiera de sus versiones, se pretende que el conjunto de instituciones y talentos se orienten preferentemente en la dirección de favorecer las condiciones de reproducción progresiva del proceso general de "creación" de riqueza mediante el trabajo y el perfeccionamiento técnico, de manera que otros ámbitos de lo social no interfieran, no perturben tal dirección. Y las discrepancias entre la versión conflictiva (marxista) y armónica (smithiana) versan sobre el cómo, no sobre el qué12, el "crecimiento" material mediante el trabajo.

Entendemos "republicanismo" en el sentido más amplio e inclusivo, como todas aquellas concepciones del sujeto que lo conciben centralmente como integrante de pleno derecho de una comunidad política de iguales ("Estado de ciudadanía y democrático", "República") en la que los derechos, responsabilidades, premios y castigos se distribuyen según el criterio de la equidad, y las instituciones y capacidades se orientan en la dirección

12. Puede ser representativa al respecto la posición de Friedrich Hayek, conspicuo liberal, quien ha sostenido, como argumento último a favor de la opción liberal-capitalista frente a todas las socialistas, que los peor situados socioeconómicamente mejoran más en una sociedad capitalista que en ninguna otra (Hayek, 1990). 
preferente de la justicia distributiva ${ }^{13}$, no del aumento de bienes materiales mediante el trabajo, como es lo propio de las filosofías obreristas. En el republicanismo, este objetivo del "crecimiento", no cuestionado en sí mismo por las corrientes principales, está en función de aquel de la justicia y la equidad. En el obrerismo, sea de signo marxista o liberal, el principio de la justicia distributiva, si bien no postergado formalmente, queda orientado en la dirección que le imprime el objetivo máximo de la mejora de las condiciones materiales de la sociedad y el "desarrollo de las fuerzas productivas". Y, por cierto, mientras que las orientaciones republicanistas ${ }^{14}$ cobran su sentido pleno en el marco conceptual de la "comunidad política", el obrerismo alcanza su sentido propio en

13. La justicia distributiva es una consecuencia lógico-racional del principio axiomático de la igualdad esencial de todo ser humano, de la que parte toda la filosofía política y el derecho modernos. Las palabras con las que arranca el libro más conocido de John Rawls son paradigmáticas: "La justicia es la primera virtud de las instituciones sociales, como la verdad lo es de los sistemas de pensamiento. Una teoría, por muy atractiva, elocuente y concisa que sea, tiene que ser rechazada o revisada si no es verdadera; de igual modo, no importa que las leyes y las instituciones estén ordenadas y sean eficientes: si son injustas han de ser reformadas o abolidas. Cada persona posee una inviolabilidad fundada en la justicia que ni siquiera el bienestar de la sociedad en conjunto puede atropellar" (Rawls, 1978: 17). Esta posición de principio de Rawls lo es en realidad de todo el liberalismo político. Queremos llamar la atención sobre la enorme diferencia entre este postulado de partida del mejor liberalismo político y el del liberalismo económico, que, como se ha visto en la nota anterior a propósito del representativo Hayek, erige como última ratio de la bondad de un sistema sociopolítico, la promoción y generalización del bienestar material. En base a esto es que podemos afirmar que el liberalismo económico participa del obrerismo, porque se legitima en su pretensión de opulencia material para la creación de empleo (o viceversa). Y más: si bien el liberalismo político ha sido discutido, y es discutible, como lo han hecho por ejemplo Robert Bellah, Charles Tylor y Michael Walzer, desde posiciones llamadas "comunitaristas", (Pérez, J, 2003) el aserto de que la justicia es la primera virtud de las instituciones sociales constituye también para estos el punto de partida de sus posiciones.

14. Valga aclarar que entendemos por republicanismo, en el sentido más amplio, todas aquellas concepciones del sujeto que lo conciben centralmente como integrante de pleno derecho de una comunidad política de iguales ("Estado de ciudadanía y democrático", "República”). Esta construcción de los sujetos actúa de cimiento para dotar de legitimidad las acciones y demandas que emprenden en la comunidad política en tanto que copartícipes iguales, legitimidad sustanciada en el derecho positivo y en la cultura política con mayor o menor solidez según los Estados y épocas. En las últimas décadas, esta concepción republicanista es el suelo sobre el que se han desarrollado los llamados "nuevos movimientos sociales" (Riechmann, J., Fernández Buey, F., 1994; Riechmann, J. 1994). 
el marco de la "sociedad", dos conceptos en ningún modo sinónimos ${ }^{15}$.

En tanto que ciudadanos, los sujetos invocan su derecho a participar en igualdad en la conformación de la polis, de la comunidad política. En tanto que obreros o emprendedores (patronos y después empresarios se hicieron llamar antaño) invocan su derecho a "producir" o "crear riqueza". La división estructural de nuestras sociedades que privilegia la perspectiva republicanista es la que distingue dominantes y dominados, o, en cualquier caso, sujetos con diferente poder formal y/o efectivo; los obreristas la dividen en población activa y no activa (que contribuyen o no al supuesto proceso de “creación de riqueza”) y, dentro de la activa, según las versiones, conciben el par patrón obrero en tensión más o menos conflictual o armónica. El republicanismo no cuestiona de partida ningún objetivo, sino si ha sido tomado respetando el principio de igualdad política.

La distinción analítica que venimos realizando entre republicanismo y obrerismo es, entendemos, pertinente, aunque en la realidad no se dé la distinción pura en ningún caso y lo que predomine sea más bien la amalgama heteróclita y polifónica. Es pertinente porque nos permite, siquiera tendencialmente, discernir qué sentido general dominante y qué orientación política tienen las manifestaciones públicas de la gente, como estas que nos ocupan.

Pues bien, como ya señalamos en la primera parte, el comienzo y final del ciclo analizados son tendencialmente obreristas, mientras el 15 de mayo representa el cenit de lo republicanista. Visto así, podría pensarse que el republicanismo indignado sería solo un paréntesis de una normalidad o convencionalidad obrerista, un "episodio pasajero" que habría aquejado a una sociedad de laborantes y emprendedores que se reconocen cómodos en tales hábitos. Caben, sin embargo, otras lecturas: un juicio muy extendido (sea visto en positivo o en negativo) entre articulistas de prensa y analistas sociales viene considerando que las movilizaciones indignadas han comportado un alto contenido

15. Creemos con H. Arendt que hay un deslizamiento, incluso un error, ya consumado en Tomás de Aquino, en la traducción del concepto zoon politikon de la Política de Aristóteles por el de animal socialis, que revela, según ella, hasta qué punto se había perdido ya en la Edad Media el original concepto griego sobre la política. La palabra "social" es de origen romano y carece de equivalente en el lenguaje y pensamiento griegos. En el mundo de Aristóteles y Platón, no se consideraba un rasgo específicamente humano la condición que los romanos llamaban social, sino algo común a muchos animales. Es la capacidad para constituirse consociativa, arbitraria y convencionalmente (políticamente) la que Aristóteles y sus contemporáneos consideraban específica y definitoria de lo humano (Arendt, 1996: 39). 
impugnador y han sido portadoras de ese "aura" que da la novedad y la sorpresa ${ }^{16}$. Para una parte mayoritaria de esta literatura, el obrerismo sindicalista representaría la continuidad o la normalidad, una protesta integrada, a la postre incluso conservadora. Es decir, una lucha, sí, pero "dentro del régimen", no "por el régimen" (Duverger, 1973), que sí habrían representado las movilizaciones de los indignados.

El obrerismo sindicalista sería pues, en el fondo, conservador, y no tanto, o no solo por la condición tibia de las demandas de las centrales sindicales llamadas mayoritarias, sino, más en el fondo, más estructuralmente: porque el obrerismo ha venido a ser un elemento integrante del orden dominante, del estado de cosas normal de las sociedades occidentales. Esto por una razón esencial, de orden paradigmático, es decir, constitutiva del orden de sentido establecido: porque el axioma de que los seres humanos estamos aquí para contribuir a la creación de riqueza trabajando es compartido por los que hemos llamado (para entendernos) "mundo del trabajo" y "mundo del capital". De ser pertinente esta interpretación, habría que concluir que, a la postre, no se trataría de dos "mundos" sino de uno solo estructurado en mitades que se complementan. Afirma H. Arendt, en su texto citado: "Nos enfrentamos con la perspectiva de una sociedad de trabajadores sin trabajo, es decir, sin la única actividad que les queda. Está claro que nada podría ser peor" (Arendt, 1996: 17). Si a esto añadimos que la idea de trabajo ha perdido toda la fuerza que hasta los años cincuenta o sesenta del pasado siglo tuvo como motivo utópico ${ }^{17}$ podemos explicarnos que las movilizaciones obreristas encabezadas por los representantes sindicales no susciten ningún interés polémico, lo que resalta en contraste vívido con el eco que perdura (sea visto positiva o negativamente) de las movilizaciones de los indignados del 15-M, porque en estás sí hubo aliento impugnador, un cuestionamiento integral del estado de cosas y de la concentración del poder, y una desacreditación de las élites gobernantes, incluidas las sindicales, y, si hubo obrerismo, estuvo subsumido en algo que lo trascendía.

Esta perspectiva nos permitiría sostener una afirmación, a título de hipótesis por demostrar: la efervescencia del republicanismo indignado entre el 15 de mayo de 2011 y comienzos de septiembre de 2012 no habría sido un episodio pasajero, sino la

16. El volumen de libros y sobre todo de artículos en revistas especializadas, y de monográficos, es ya abrumador, en llamativo contraste con el escaso interés que para los especialistas despiertan las expresiones de descontento obrero, como no sea entre quienes se ven obligados de oficio a escribir en la prensa escrita la crónica de la última manifestación obrera y el resumen de las invectivas de los líderes sindicales.

17. "La estructura del espíritu de la época no ha cambiado, como tampoco lo ha hecho la forma de la polémica sobre posibilidades vitales futuras y la conciencia histórica no está perdiendo las energías utópicas en modo alguno. Antes bien, lo que ha llegado a su fin ha sido una utopía concreta, la que cristalizó en el pasado en torno al potencial de la sociedad del trabajo" (Habermas, 1994: 37). 
exteriorización de un mal de fondo, de un problema estructural de nuestra sociedad que, sin embargo, permanece oculto porque, salvo ese episodio y algunos otros anteriores (manifestaciones contra la guerra de Irak...) el obrerismo convencional y sus liturgias callejeras periódicas entorpece u obstaculiza que se manifieste. La dialéctica de enfrentamiento acostumbrada y convencional, entre los gobiernos y la patronal por un lado y los sindicatos y partidos obreristas por otro, ha llegado a ser hace tiempo un escenario rutinario: rebeliones ritualizadas, al modo como lo analizó Gluckmann para otro tipo de sociedades (Gluckmann, 1971). Por eso, cuando ha tenido lugar la última huelga general en respuesta a la última reforma laboral, los "mundos" que hemos llamado del "capital" y del "trabajo", ambos, se han reconocido mutuamente de nuevo y han recuperado el sitio respectivo que el estado "normal" de nuestras sociedades les viene reservando desde hace muchas décadas. El republicanismo del 15-M los desplazaba y denunciaba a esas dos mitades al proponer otra definición del conflicto fundamental.

\section{El simbolismo de las movilizaciones}

Estudiaremos ahora el ciclo de movilizaciones elegido desde otro ángulo, para también desde éste evidenciar la amplia heterogeneidad entre el obrerismo de las huelgas de inicio y fin del ciclo y las acciones republicanistas del 15-M. Analizaremos el tipo de acciones simbólicas predominantes en el espacio público durante el período: han tenido lugar sobre todo, sea por su capacidad de convocatoria o por su número y perseverancia, huelgas de trabajador@s, marchas y acampadas de ciudadan@s que reclamaban democracia real o preservación de la educación y la sanidad públicas (las "mareas"), y concentraciones contra los desahucios de viviendas. Pero, antes de abordar el simbolismo de cada una, conviene señalar algo que vale para todas y aún para cualquier otra forma de expresión de descontento en la calle: el haz potencial de significados asociados a cualquier forma de congregación de personas en la calle en la contemporaneidad cobra sentido en el marco del Estado moderno postrevolucionario, que lo construye como comunidad política de sujetos iguales ante la ley y con competencia política: iguales jurídicos, iguales formales, no materiales, es decir, iguales conforme al contrato político que constituye a la comunidad, no conforme a otros contratos mercantiles o patrimoniales. Es este marco normativo el que crea el espacio público o ágora, en el que asiste a los reconocidos como ciudadanos la potestad de expresarse e intervenir políticamente. Merced a esta condición fundante, las calles y plazas ya no son solo intersecciones que comunican lugares y propiedades, sino ellas mismas lugares comunes, inter-nos, vale decir públicos; en definitiva: políticos, por contraposición a privados o de nadie. Es esta condición la que posibilita que los cualificados políticos (los ciudadanos) comuniquen a sus conciudadanos y a sus representantes cualquier contenido sobre las materias comunes o inter-nos por medio de la congregación en esos lugares públicos. Por tanto, es el Estado así constituido el que crea las condiciones para la manifestación política, que es otra cosa 
que un motín, una algarada o cualquier suceso callejero. Necesariamente, en cualquier manifestación política, sea de un colectivo o de un individuo, la interpelada y concernida es el conjunto de la comunidad política y en primera instancia sus representantes elegidos. Dado que en estas formaciones políticas modernas -a diferencia de la polis griega, donde sí era posible la relación cara a cara en el espacio público-, es materialmente imposible la congregación efectiva de los concernidos en el espacio público, los medios de comunicación han venido asumiendo un cometido fundamental de difusión (filtrada, sesgada, según sus propietarios) de estos acontecimientos políticos, amén de otros de distinta naturaleza, desde sus orígenes precarios de pasquines hasta la sofisticación y diversidad actual.

Todos los actores con propuestas e intereses políticos -actores colectivos en todos los casos, como partidos, sindicatos, grupos de presión- tienen una necesidad imperiosa de ganar espacio y/o condicionar a los medios, auténtica tribuna de nuestras comunidades políticas. Pero, dada la efectiva distribución desigual del poder en ellas, mientras unos actores, los dominantes, tienen acceso privilegiado a esas tribunas -las controlan, las condicionan-, otros, los minorizados, los excluidos, los dominados, solo las alcanzan si se hacen oír fuerte y con perseverancia en la calle (Chomsky, 1990; Calviño, 1995; Castillo Vargas, 2000), de manera que esos espacios públicos son utilizados por los sujetos políticos -si logran reunir número y fuerzas- para hacerse oír ante sus iguales (jurídico-políticos) cada vez que entienden que las tribunas mediáticas y los cauces institucionales del gobierno les desatienden. Los tipos de acciones que se registraron en el espacio público del Estado español en el período considerado tienen todas este fin fundamental, si bien las huelgas tienen cierta especificidad que señalaremos en seguida. La manifestación, en el sentido moderno, es cualquier concentración de uno o más sujetos políticos en el espacio público -o de personas que no poseen el estatus de ciudadanía pero pretenden que esa condición se haga extensiva a ellos, o incluso universalcon el fin de comunicar su criterio y posición al conjunto de la ciudadanía y/o a los representantes gubernamentales empleando cualesquiera procedimientos expresivos a tal fin ${ }^{18}$. Reciben distintos nombres según sean los medios y procedimientos empleados

18. José M. Casquete define así la manifestación: “una reunión en la esfera pública con vocación de ejercer influencia política, social y/o cultural sobre las autoridades, la opinión pública o los propios participantes, mediante la expresión disciplinada y pacífica de una opinión o demanda. Idealmente, aunque no necesariamente, los lugares públicos en los que discurren las manifestaciones combinan alta visibilidad y relevancia simbólica" (Casquete, 2005: 107). 
(concentración, manifestación, acampada, marcha...) ${ }^{19}$. Por tanto, la manifestación es un hecho genuinamente ciudadano, más que específicamente obrero, y cuando es una manifestación obrerista -como lo han sido en el período que consideramos las últimas que cerraron la jornada de huelga de marzo de 2012 contra la reforma laboral del PP-, los ciudadanos se invisten de obreros, de ciudadanos centralmente obreros, como explicaremos enseguida.

Han sido las acampadas, tan llamativas y centrales en las movilizaciones de los indignados del 15-M, las que les han otorgado un perfil singular y distintivo a sus acciones. En ellas es donde se ha hecho más incisiva esa condición de raíz ciudadana, o republicana, de ciudadanos que reclaman recuperar y pertenecerles definitoriamente lo que consideran usurpado: el derecho a decidir en igualdad sobre el futuro de la comunidad política. Las acampadas celebraban diariamente asambleas, y parecería que eran en sí mismas asambleas permanentes. Pero no: eran manifestaciones permanentes que utilizaban como medio expresivo la forma asamblearia para comunicar a la ciudadanía toda que las decisiones corresponden a la comunidad política en su conjunto y que está actualmente usurpada por representantes espurios. El simbolismo de esas simulaciones de asambleas que se sucedían esos días en las acampadas de las plazas es muy revelador: como tales acampadas, tendían ellas mismas a asemejarse a asambleas permanentes, o un ágora de deliberación y propuestas plurales sobre lo colectivo y lo político. Eran, antes que un procedimiento de organización de las acampadas y de toma de decisiones, una acción plena de significación proclamatoria al conjunto de la ciudadanía, y en ello ha estado probablemente su mayor eficacia, con no ser poca la demostrada en lo organizativo y resolutivo: surgían casi espontáneamente en todas las plazas, con una espacialidad carente de centro y radialidad, sin coro de palmeros y vitoreadores, más deliberativas que resolutivas, alérgicas a las parrafadas, con procedimientos rotativos y horizontales de asignación de $\operatorname{cometidos}^{20}$. Por tanto, lo inverso de los mítines y discursos de los

19. El contenido expresivo de las manifestaciones puede oscilar entre la denuncia puntual yla impugnación total del orden establecido, pero tienen siempre una orientación crítica en algún grado. Deben ser distinguidas pues de los actos aclamatorios, en los que la congregación pública de sujetos cualificados tiene por fin fundamental la reafirmación del estado de cosas de la comunidad política y el apoyo a los jerarcas y sus directrices. Ello aunque el lenguaje común no las distinga a menudo ("manifestaciones de la Plaza de Oriente" de Madrid durante la dictadura de Franco, "Manifestación del 1 de mayo" en la plaza Roja de Moscú en la URSS, etc) y ejemplos concretos puedan considerarse una transición entre ambos tipos. Max Weber señaló que todas las formas de dominación que presentan una componente carismática importante requieren de periódicas ceremonias de corroboración o aclamatorias (Weber, 1993: 193 y sig.).

20. Moreno Pestaña ofrece una interpretación diferente a la aquí propuesta del asambleísmo del 15M, no contradictoria, sino complementaria y enriquecedora (Moreno Pestaña, 2013). 
cuadros y jerarcas de los partidos y sindicatos, con su escenografía axial, las parrafadas y monólogos del oficiante, cerradas en palmas y vítores de todos los demás que ocupan los extremos del haz radial con centro en él (Talego-Vazquez, F.; Rio-Sanchez, A. del; Coca-Perez, A., 2012).

El asambleísmo del 15-M no era, no podía ser, un proceder resolutivo o ejecutivo, porque no había nada allí que ejecutar que no fuera sobre la propia concentración, dada la carencia absoluta de autoridad y jurisdicción efectiva de las personas congregadas sobre las materias a cerca de las cuales no obstante se deliberaba entusiasta, exaltadamente, y se votaba: reforma de la Constitución, del Tratado de la Unión Europea, de las reglas de los mercados financieros, de nuevas formas de agricultura, de políticas de vivienda, de la sanidad o educación públicas... ¿Acaso ignoraba la multitud "asambleada" que carecía de aquellas competencias? Muy al contrario, la gente del 15-M denunciaba, impugnaba, que las decisiones sobre todas esas materias se les habían arrebatado, se habían venido tomando sin su concurso, y reclamaban su restitución a la ciudadanía. Esto explica que en unas y otras de las asambleas, con precipitación indudable, sin coordinación suficiente entre acampadas, se aprobasen abundantes resoluciones sobre materias fundamentales, que, vistas de cerca, una a una, resultan a menudo impracticables, contradictorias, descabelladas incluso: porque no se trataba en el fondo de qué hacer, sino de que, lo que hubiera de hacerse, tendría que ser con la participación efectiva de la ciudadanía, que había convergido en las plazas indignada por sentir que este derecho político esencial estaba secuestrado.

Necesario es recordar además que la apoteosis de las acampadas indignadas se produce en medio de la campaña electoral a las municipales de 2011. Este hecho contribuyó a elevar el potencial impugnador de las acampadas, pues ensombrecieron a los mítines de los jerarcas partitocráticos: las asambleas indignadas fueron entonces el reverso o inversión simbólica de los mítines, porque su escenografía y procedimientos referidos eran el 
reverso de éstos. Téngase en cuenta que las elecciones son el gran ritual aclamatorio ${ }^{21}$ reinstaurador de legitimidad de los regímenes democráticos, y los indignados habían logrado introducirse y modificar el normal discurrir del mismo. Era la primera vez que un hecho así ocurría en el régimen de la monarquía parlamentaria española y son escasos los precedentes en Europa Occidental.

Las concentraciones contra los desahucios de viviendas a familias sin recursos han sido una de las expresiones que más tiempo y más eco mediático y social han tenido y siguen teniendo una vez que han cesado - hasta hoy- las grandes manifestaciones de los indignados. Puede afirmarse de hecho que estas concentraciones antidesahucios, junto con las conocidas como "mareas" en defensa de los servicios públicos, han venido a ser el testimonio principal de que sigue vivo el espíritu del 15-M. Al no haberse instituido una entidad que invoque y sea reconocida como representativa de los indignados ${ }^{22}$, el 15-M y su espíritu solo pervive en tanto que gentes se congreguen en el espacio

21. La acclamatio romana, que heredó la iglesia católica en diversas formas, especialmente en la aclamación del nuevo Papa tras la fumata blanca. Los ceremoniales de los Estados modernos, y en particular el principal de las convocatorias electorales, deben ser considerados, en un primer nivel de análisis, ritos políticos que convocan lo sagrado y sacralizan, entendiendo sacralidad, en sentido genérico, como lo primigenio y la razón de ser. Aunque muchos autores cuestionan que sean aplicables estas categorías de lo religioso a la realidad de los estados modernos postrevolucionarios (Goody, 1977; Cruces, 1999), fue el propio Rousseau el primero que habló de "religión civil" en El contrato social (Bellah, 1967) y Durkheim sostuvo que hay un sustrato religioso en el formalismo jurídico: "Hay, pues, en la religión algo eterno... No puede haber ninguna sociedad que no sienta la necesidad de mantener y revitalizar, a intervalos regulares, los sentimientos colectivos y las ideas colectivas... mediante reuniones, asambleas y congregaciones en las que los individuos... reafirman en común sus sentimientos comunes: de ahí la existencia de ceremonias que, por su objeto, por los resultados que obtienen y por los medios que emplean para ello, son de la misma naturaleza que las ceremonias religiosas propiamente dichas" (Durkheim, 2003: 75, 641). Entre los autores que se adscriben a esta fértil metodología para el análisis de los ceremoniales contemporáneos, cabe destacar a D. Kertzer (Kertzer, 1989) o G. Balandier (Balandier, 1994). Entre los muchos análisis de caso que recurren a la categoría de lo ritual y lo sagrado en contextos contemporáneos, podemos destacar el estudio de las ceremonias de dignificación instauradas por la Revolución Bolivariana venezolana (Vasquez, 2007), o el análisis de las "caminatas" argentinas, otorgadoras de carisma político (Herkovits, 2005); o el análisis del proceso a los excomandantes de la dictadura argentina en clave de ritual político (Kaufman, 1987); o el análisis de las luchas por el acceso a la tierra de los jornaleros en Andalucía (Talego, 1996).

22. Este déficits de representatividad, o mejor, de cristalización institucional del 15-M no es consecuencia de debilidad sino la traducción de la condición polifónica y heterogénea que lo caracteriza y, sobre todo, de la extendida inclinación antiautoritaria característica de los nuevos movimientos sociales o, lo que es lo mismo, de los movimientos no obreristas. 
público y lo invocan para cualquier propósito que se reconozca como proyección y continuidad de la esencia republicanista y antiautoritaria que lo caracteriza (Del Rio, A., Talego, F., Coca, A., 2012). Y esto es justamente lo que están representando las acciones antidesahucios, si no surgidas sí extendidas y multiplicadas desde los días mismos de las grandes concentraciones indignadas, reconocidas por tirios y troyanos como herederas del 15-M. Pues bien, en orden a nuestra argumentación, queremos llamar la atención sobre alguno de los significados que de esto cabe extraer: invocar como se invoca en estas concentraciones el derecho a una vivienda para toda persona, por su sola condición ciudadana y con independencia de cualquiera otras circunstancias es puro republicanismo, pues se otorgan al sujeto derechos (derecho a la vivienda en este caso) por la sola razón y suficiente de su pertenencia a la comunidad política. Lo mismo puede afirmarse del derecho al trabajo, que, como hemos señalado, no ha dejado de invocarse en las manifestaciones de los indignados. Si bien -y esta es la cuestión- los despidos y cierres patronales que se vienen sucediendo no están suscitando la sensibilidad de los indignados, que no acuden a solidarizarse con los despedidos, o solo contada y esporádicamente. Como se constata sucesivamente en la prensa, las protestas por despidos y cierres patronales son secundadas poco más que por los afectados, sus familias y la tropa de turno reclutada entre los miembros menores de las centrales sindicales.

¿Qué significaesta distinta receptividad de quienes siguen movilizándose como indignados ante la pérdida por conciudadanos de derechos reconocidos en las constituciones: el del trabajo y el de la vivienda? No parece suficiente explicación argüir el escepticismo generalizado e incluso desesperanza que se ha instalado en la ciudadanía sobre las posibilidades de revertir el desempleo. Porque no se ve por qué tendría que ser menos el escepticismo e incredulidad de poder trasformar la vivienda en un derecho efectivo desde su aplastante realidad presente de mercancía. La respuesta a la interrogante no puede ser taxativa o cerrada: porque la realidad es fluida y las motivaciones y movimientos de los actores no son estancos. Pero el hecho está ahí e indica tendencialmente que el reclamo amplio de derechos del 15-M no tiene por centro y eje la exigencia de trabajo. Y más: los derechos que vienen demandando los indignados basculan sobre el eje de la condición ciudadana común y postergan las clasificiones derivadas de la cosmovisión obrerista (trabajador, parado, activo, pasivo...).

La otra forma de acción colectiva presente en el período que consideramos es la huelga, la más propia y definitoria del obrerismo: nace en ambientes obreros (mineros, fabriles) como medio de presión, dirigida expresamente contra los patronos, para obtener de ellos mejoras laborales y salariales. En cuanto tal, no tiene un contenido directa o al menos primariamente político, pues es en germen y en origen un medio de presión privado que fue siendo regulado en las distintas legislaciones estatales a lo largo del siglo XIX, y en dicha medida politizándose. Y sería el desarrollo de los socialismos en la misma centuria el que politizaría decisivamente este medio de presión, especialmente en su 
reinterpretación como huelga revolucionaria o huelga general (Sorel, 1912; AA.VV, 2005). Pero, en cualquiera de sus modalidades, desde las menos a las más directamente políticas, la huelga ha conservado un carácter eminentemente obrero, obrerista, o, en un sentido más amplio, laboralista.

En el ciclo que hemos analizado, el inicio y el final está señalado por dos huelgas generales. Ello parecería avalar, ahora desde este ángulo de las acciones en el espacio público, la tesis de la prevalencia general del obrerismo con un episodio excepcional o anómalo de republicanismo. Pero ello es cuestionable, pues las huelgas generales referidas, como es lo común en las huelgas generales habidas en España desde la Transición, son huelgas breves, de un día, y su significado tiene poco que ver con las miras revolucionarias que tuvo la huelga general en los orígenes del movimiento obrero y recoge por ejemplo el conocido texto citado de Georges Sorel (1912). Si observamos las dos huelgas con algo más de detenimiento, podremos concluir que tienen más de manifestación política que de huelga propiamente dicha: una huelga de un día no compromete ni pretende comprometer el beneficio empresarial, sino que persigue el paro masivo en los tajos y la manifestación masiva de cierre como expresión simbólica de respaldo del mundo laboral a las propuestas de los sindicatos convocantes, de contenido político. Encierran el implícito fundamental de que ese "mundo del trabajo" convocado e invocado es el centro, la expresión cardinal del conjunto de la ciudadanía, y no tanto o no sólo por razón de número sino por la autoridad diferencial que las ideologías obreristas otorgan a los trabajadores, quienes serían los auténticos artífices del "crecimiento", la prosperidad y todo eso.

Pero en estas huelgas generales de un día, el implícito referido está encriptado en formas y procedimientos que corresponden a lo que hemos caracterizado como manifestación en el marco de la comunidad política constitutiva de la ciudadanía. Es este marco el que dota de plausibilidad e inteligibilidad tanto el implícito canónico común a todas las huelgas (el "mundo del trabajo" tiene precedencia en el conjunto de la ciudadanía) como los mensajes autorreferenciales singulares de cada una (en las dos huelgas analizadas, el 
rechazo a las reformas laborales ${ }^{23}$. En definitiva, se trata de rituales ciudadanos en los que estos aceptan investirse centralmente como obreros, pues, no en vano, según nos hizo ver $\mathrm{H}$. Arendt, han sido socializados como tales, de manera mucho más incisiva y profunda que como sujetos de derechos políticos (Arendt, 1996: 17). Pero no debe ocultársenos que subyace a estos ropajes obreristas una debilidad congénita del mundo y de las utopías del trabajo. Y en fin, esta deriva de las huelgas generales en España -como en el resto de Europa- muestra con claridad que nuestras sociedades han ido basculando desde el obrerismo al republicanismo.

Ahora bien -y esto es clave- en tanto que la ciudadanía es convocada y acepta ${ }^{24}$ expresarse en el espacio público preferente o exclusivamente como obrera, todos los descontentos y propuestas sobre la cosa pública en general quedan subsumidos y encauzados por este obrerismo venido a menos, consumándose un estado de cosas en que lo genéricamente ciudadano se mantiene rehén de lo específicamente obrero. Siendo esto así, debemos concluir que, en el período considerado de protestas ciudadanas, el obrerismo representado por las huelgas ha venido a ocluir -disminuir, encauzar, domesticar- el rosario de propuestas ciudadanas que, tomadas en conjunto - $y$ aun aisladamente algunas de ellas-, alcanzaban un alto contenido impugnador.

23. Edmund Leach afirma que los actores sociales participan en rituales para transmitirse a sí mismos mensajes colectivos e información sobre la posición social de cada uno, y que, a su vez, la ejecución de tales rituales provoca cambios o bien reactiva el estado (metafísico) del mundo (Leach, 1989: 62; 69). Esta tesis sirve a su vez de punto de partida a Roy Rappaport, quien llama autorreferenciales a esos mensajes que transmiten información sobre la posición y especificidades de os participantes. Pero, según él, el ritual incorpora otro tipo de mensajes que no codifican para cada caso los participantes, sino que están ya codificados por la liturgia y tienden hacia la invariabilidad. Son los mensajes canónicos, que no están limitados al aquí y al ahora, sino que incluyen, en palabras y actos que han sido dichos y ejecutados antes, órdenes, procesos o entidades, materiales o abstractos, la presencia o pretendida existencia de lo que trasciende lo presente. Lo canónico representa lo pretendidamente invariable (Rappaport, 2001: 95-98). 24. Véase la nota 10 para la diferencia entre "aceptar" y "creer" en contextos rituales. 


\section{REFERENCIAS BIBLIOGRÁFICAS}

AA.VV. (2005) Estudios sobre la huelga. Albacete: Ediciones Bomarzo.

Arendt, H. (1996) La condición humana. Barcelona: Paidós.

Balandier, G. (1994) El poder en escena. De la representación del poder al poder de la representación. Barcelona: Paidós.

Bellah, R. N. (1967) “Civil Religion in America”. Daedalus, 96 (1).

Calviño, J. M. (1995) Los medios de comunicación social hoy. Del Leviatán a los Reyes Magos. Madrid: Temas para el debate.

Casquete, J. M. (2005) "Manifestaciones e identidad colectiva”. Revista Internacional de Sociología, 42, pp. 101-125.

Castillo Vegas, J. L. (2000) "Democracia mediática, concentración de los medios de comunicación y mentira política”. Anales de la Cátedra Francisco Suárez, 34, pp. 29-43. Chomsky, N. y Herman, A. S. (1990) Los guardianes de la libertad. Barcelona: Crítica. Cruz, F. (1999) "Notas sobre la problemática del concepto de ritual en el estudio de las sociedades contemporáneas". En Salvador Rodríguez Becerra (coord.) Religión y cultura, Vol I. Sevilla: Fundación Machado, pp. 513-528.

Della Porta, D. y Dioni, M. (2011) Los Movimientos Sociales. Madrid: Editorial Complutense y Centro de Investigaciones Sociológicas.

Díez, F. (2001) Utilidad, deseo y virtud. Barcelona: Península.

Durkheim, E. (2003) Las formas elementales de la vida religiosa. Madrid: Akal.

Duverger, M. (1973) Sociologie de la politique. Eléments de Sciencie politique. París: Presses Universitaires de France.

Gluckmann, M. (1971) Order and rebellion in tribal Africa: collected essays with an autobiographical introduction. London: Cohen \& West.

Goody, J. (1977) "Against Ritual: Loosely Structure Thoughts on a Loosely Defined Topic".

En S. Moore. y B. Myerhoff (eds.) Secular Ritual. Assem: Van Gorcum, pp. 25-35.

Gorz, A. (1991) La metamorfosis del trabajo. Búsqueda del sentido. Madrid: Sistema.

Habermas, J. (1994) Ensayos políticos. Barcelona: Ediciones Península.

Hayek, F. (1990) La fatal arrogancia: los errores del socialismo. Madrid: Unión Editorial. Johnston, H.; Laraña, E. y Gusfield, J. (1994) "Identidades, ideologías y vida cotidiana en los nuevos movimientos sociales". En E., Laraña y J., Gusfiled (eds.) Los nuevos movimientos sociales: de la ideología a la identidad. Madrid: CIS, pp. 3-42.

Kaufman, E. (1987) Análisis ritual de una audiencia del juicio a los ex-comandantes. Buenos Aires: FLACSO.

Kertzer, D. (1988) Ritual, Politics and Power. New Heaven: Yale University Press.

Leach, E. (1989) Cultura y comunicación: la lógica de la conexión de los símbolos. Madrid: Siglo XXI. 
Melucci, A. (1980) “The New Social Movements: a theoretical approach”. Social Science Information, 19, pp. 199-226.

Melucci, A. (1985) “The symbolic challenge of social movements”. Social Research, 52(4), pp. 789-816.

Melucci, A. (1994) “¿Qué hay de Nuevo en los nuevos movimientos sociales?”. En E. Laraña y J. Gusfiled (eds.) Los nuevos movimientos sociales: de la ideología a la identidad. Madrid: CIS, pp. 119-149.

Moreno Pestaña, J. L. (2013) Democracia, movimientos sociales y participación popular. Lógicas democráticas y lógicas de distinción en las asambleas del 15M. En Javier Escalera y Agustín Coca (coords.) Movimientos sociales, participación y ciudadanía en Andalucía. Sevilla: Aconcagua.

Morris, B. (1995) Introducción al estudio antropológico de la religión. Barcelona: Paidós. Munford, L. (1971) Técnica y civilización. Madrid: Alianza.

Naredo, J. M. (1995) La economía en evolución: Historia y perspectivas de las categorías básicas del pensamiento económico. Madrid: Siglo XXI.

Naredo, J. M. (2010) Raíces económicas del deterioro económico y social. Madrid: Siglo XXI.

Pérez, J. (2003) Comunitarismo. Madrid: Sekotia.

Rappaport, R. A. (2001) Ritual y religión en la formación de la humanidad. Cambridge: University Press.

Rawls, J. (1978) Una teoría de la justicia. México: FCE.

Riechmann, J., Fernández Buey, F. (1994) Redes que dan libertad. Introducción a los nuevos movimientos sociales. Barcelona: Paidós.

Riechmann, J. (1994) Los verdes alemanes. Granada: Comares.

Roca, B.; Díaz, I. (2012) "De la tierra a los supermercados: el SAT como ejemplo de particularismo militante y de renovación sindical". Anuari del Conflicte Social http:// www.observatoridelconflictesocial.org/ [Consultado el 12 de diciembre de 2013].

Sorel, G. (1912) Reflexiones sobre la violencia. Madrid: Alianza.

Talego, F. (1996) Cultura jornalera, poder popular y liderazgo mesiánico. Antropología política de Marinaleda. Sevilla: Universidad de Sevilla y Fundación Blas Infante.

Talego-Vazquez, F; Rio-Sanchez, A. del; Coca-Perez, A. (2012) “PPor qué no nos representan? Simbolismo del Movimiento 15-M". En REBELIÓN http://www.rebelion. org/ [Consultado el 10 de diciembre de 2013].

Tilly, C. (2005) “Los movimientos sociales entran en el siglo veintiuno”. Política y Sociedad, 42(2), pp. 11-35.

Weber, M. (1969) La ética protestante y el espíritu del capitalismo. Barcelona: Península. Weber, M. (1993) Economía y sociedad. Esbozo de sociología comprensiva. Madrid: FCE. 